\title{
COLLEGE EVENTS
}

\section{'Uses of Television in Psychiatry'}

A Conference to consider the various applications of television in the field of psychiatric education will be held at the University of Birmingham from 5 to 7 September 1977. It is organized jointly by the Royal College of Psychiatrists and the Association of University Teachers of Psychiatry. The Conference will be residential and the fee of $£ 30$ will cover complete board and lodging in the University Halls of Residence and the Conference Dinner. The number of participants will be limited to 200 and priority will be given to those actively engaged in undergraduate and postgraduate teaching, including all psychiatric tutors. Applications should be sent to Dr T. A. Betts, University Department of Psychiatry, Queen Elizabeth Hospital, Birmingham, Br5 2 TH.

\section{A Course on Research Methodology and Statistics}

A Course on Research Methodology and Statistics, sponsored jointly by the Research Committee of the Royal College of Psychiatrists and the Department of Psychiatry at Manchester University, will be held at the University Hospital of South Manchester on $5 / 6$ and $26 / 27$ November 1977 .

The Course will consist of lectures and seminars on research methods, together with exercises in statistics and the writing of research protocols.

Numbers will be limited to 30 . Those interested should write to Mrs G. Scott, Administrator, Department of Psychiatry, University Hospital of South Manchester, West Didsbury, Manchester M20 8LR.

\section{East Anglian Division}

The next Scientific and Business Meeting of the Division will be held at the Tavistock Centre,
120 Belsize Lane, London NW3 5 BA, on Thursday, 22 September.

\section{Child Psychiatry Section}

The 1977 residential conference of the Section will be held at the David Russell Hall of the University of St Andrews from 16-18 September. The Conference fee is $£ 25.00$, covering accommodation for two nights, self-service meals and the Conference Dinner, including wines. Registration forms and further details, including those of reduced rail fares for group travel, from Dr Ian C. Menzies, Polyclinic Area 2a, Ninewells Hospital and Medical School, Dundee, DD2 I UB, Scotland. Places can be guaranteed for all applications received before 15 August.

\section{Photographs from the Reception}

Members who attended the Reception held at College Headquarters on 5 July may like to know that the photographs taken there will be on display in the waiting room at 17 Belgrave Square until the the end of August, together with order forms for the purchase of copies. 